\title{
ON THE CHEBYSHEV FUNCTIONAL
}

\author{
MAREK NIEZGODA
}

Abstract. In this paper we prove an inequality for certain orthoprojectors. For orthoprojectors of rank one we obtain a Chebyshev type inequality. Grüss-Lupaş type inequalities are also discussed.

Mathematics subject classification (2000): 26D15, 26D20, 15A39, 06F20.

Key words and phrases: orthoprojector, Chebyshev type inequality, Grüss-Lupaş inequality.

\section{REFERENCES}

[1] M. L. EATON, On group induced orderings, monotone functions, and convolution theorems, in Inequalities in Statistics and Probability (Tong Y.L., Ed.) IMS Lectures Notes Monogr. Ser., 5, (1984), 13-25.

[2] M. L. EATON, Lectures on Topics in Probability Inequalities, CWI Tract 35, Centrum voor Wiskunde en Informatica, Amsterdam, 1987.

[3] M. L. EATON, Group induced orderings with some applications in statistics, CWI Newsletter, 16, (1987), 3-31.

[4] S. IZUMino, J. E. PEČARIĆ AND B. TEPEŠ, A Grüss-type inequality and its applications, J. Inequal. Appl., 3, (2005), 277-288.

[5] A. S. LEWIS, Convex analysis on Hermitian matrices, SIAM J. Optim., 6, (1996), 164-177.

[6] A. S. LEWIS, Group invariance and convex matrix analysis, SIAM J. Matrix Anal. Appl., 17, (1996), 927-949.

[7] A. S. LEWIS, Convex analysis on Cartan subspaces, Nonlinear Anal., 42, (2000), 813-820.

[8] A. W. MARShall AND I. OLKIN, Inequalities: Theory of Majorization and Its Applications, Academic Press, New York, 1979.

[9] H. F. MiRANDA AND R. C. ThOMPSON, Group majorization, the convex hull of sets of matrices, and the diagonal elements - singular values inequalities, Linear Algebra Appl., 199, (1994), 131-141.

[10] L. NACHBIN, The Haar Integral, Van Nostrand, Princeton, 1965.

[11] M. NiEZGODA, Group majorization and Schur type inequalities, Linear Algebra Appl., 268, (1998), 9-30.

[12] M. NiEzGodA, An analytical characterization of both effective and irreducible groups inducing cone orderings, Linear Algebra Appl., 269, (1998), 105-114.

[13] M. NiEZgodA, Bifractional inequalities and convex cones, Discrete Math., 306, (2) (2006), 231-243. 